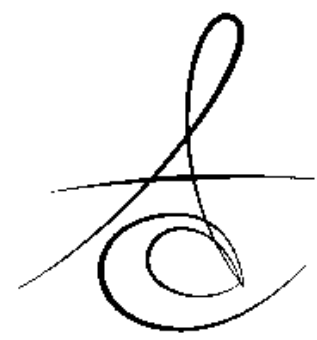

\title{
TEMPOROMANDİBULAR EKLEM OSTEOARTRİTLİ HASTALARDA ARTROSENTEZİ TAKİBEN YAPILAN TROMBOSİTTEN ZENGİN PLAZMA, HYALURONİK ASİT VE KORTİKOSTEROİD ENJEKSİYONLARININ TEMPOROMANDİBULAR EKLEM PALPASYONUNDA OLUŞAN AĞRIYA ETKİLERİNİN KARŞILAŞTIRILMASI
}

\author{
A COMPARISON OF EFFECTS OF PLATELET-RICH PLASMA, HYALURONIC ACID, \\ AND CORTICOSTEROID INJECTIONS FOLLOWING ARTHROCENTESIS ON PAIN \\ DURING JOINT PALPATION AFTER TREATMENT OF TEMPOROMANDIBULAR \\ JOINT OSTEOARTHRITIS
}

\section{Dr. Songül CÖMERT KILIÇ*}

Prof. Dr. Metin GÜNGÖRMÜş ${ }^{* *}$

Makale Kodu/Article code: 2915

Makale Gönderilme tarihi: 01.07.2016

Kabul Tarihi: 09.08.2016

\section{ÖZ}

Amaç: Bu çalışmanın amacı temporomandibular eklem (TME) osteoartritli hastalarda uygulanan 4 farklı tedavi yönteminin Temporomandibular eklemin lateral ve posterior palpasyonundaki ağrıda meydana getirdiği değişimleri karşılaştırmaktır.

Yöntem: Bu çalışmaya hem klinik inceleme ile ve hem de konik ışınlı bilgisayarlı tomografik değerlendirme (CBCT) ile TME osteoartriti (TME-OA) teşhisi konulan erişkin hastalar dahil edilmiş ve bu hastalar rastgele bir şekilde 4 farklı tedavi grubuna ayrılmıştır: sadece artrosentez (1), artrosenteze ilave yapılan trombositten zengin plazma (PRP) (2), hyaluronikasid (HA) (3) veya kortikosteroid (KS) (4) enjeksiyonları. Kontrol grubu15 dejeneratif ekleme sahip 12 hasta, PRP grubu32 dejeneratif ekleme sahip 18 hasta, HA grubu 17 dejeneratif ekleme sahip 13 hasta ve KS grubu ise 17 dejeneratif ekleme sahip 12 hasta içermiştir. Bu hastalara tedavi başlangıcında tek seans artrosentez işlemi uygulanmıştır. PRP grubunda ilave 5 seans, HA grubunda ilave 1 seans Hyalgan ve KS grubunda ilave 1 seans Depomedrol'uneklem içi enjeksiyonları uygulanmıştır. Temporomandibular eklemin lateral ve posteriorpalpasyonundaki ağrı, 5 dereceli ağrı skalası ( 0 = yok; $1=$ hafif; $2=$ orta; $3=$ yoğun; $4=$ şiddetli) kullanılarak tedavi öncesi ve tedaviden sonraki ortalama 1. yılda değerlendirilmiştir. Gruplar arası karşılaştırma Mann Whitney U testi yapılarak değerlendirilmiştir.

Bulgular: Kontrol grubu ile karşılaştııılığında, PRP grubunda posterior TME palpasyonunda, HA grubunda ise lateral ve posterior TME palpasyonunda oluşan ağrı skorlarında istatistiksel olarak daha fazla iyileşme gözlemlenmiştir. KS grubunda anlamlı bir iyileşme görülmemiştir. PRP grubunda lateral TME palpasyonunda oluşan ağrı skorlarında ise, HA ve KS grupları ile karşılaştırıldığında istatistiksel olarak daha fazla iyileşme gözlemlenmiştir.

Sonuç: Bu çalışmanın bulguları, artrosentezi takiben uygulanan eklem içi PRP enjeksiyonlarının kontrol, HA ve KS gruplarına nazaran TME palpasyonundaki ağrı üzerinde daha fazla iyileşme sağladığını göstermiştir.

Anahtar Kelimeler: Ağrı, Artrosentez, Hyaluronik asit, Kortikosteroid, TME Osteoartriti, Trombositten zengin plazma.

\section{ABSTRACT}

Aim: To compare long-term changes of pain during lateral and posterior palpation of the joint with osteoarthritis (TMJ-OA) treated with four different treatment options.

Methods: The sample composed of the adult patients with TMJ-OA met the inclusion criteria, and they were randomly divided into four groups: arthrocentesis alone (Control group), arthrocentesis plus platelet-rich plasma (PRP), arthrocentesis plus hyaluronic acid (HA), and arthrocentesis plus corticosteroid (CS) (Methylprednisolone acetate) injections. Control group consisted 15 osteoarthritic joints of 12 subjects, PRP group consis- ted 32 osteoarthritic joints of 18 subjects, CS group consisted 17 joints of 12 subjects, and HA group consisted of 17 joints of 13 subjects. Arthrocentesis was performed in the all groups. Additional five sessions PRP injections and one session HA or CS injections were performed in HA and CS groups, respectively. Pain during lateral and posterior palpation of TMJ was evaluated using five grading level scale $(0=$ absent; $1=$ slight; $2=$ moderate; $3=$ intense; and $4=$ severe) preoperatively and 12 months postoperatively. Using Mann-Whitney $U$ test used for intergroup comparisons.

Results: When compared with control group, pain at posterior palpation decreased significantly more in PRP and HA groups, pain at lateral palpation decreased significantly more only in HA group, but showed no significant difference with CS group. Significantly greater pain reduction at lateral palpation was observed in PRP group compared to HA or CS group.

Conclusions: Our findings suggested that arthrocentesis plus PRP injections produced better painrelief duringjoint palpation comparedto arthrocentesis alone, arthrocentesis plus CS or HA injections.

Key Words: Pain, Arthrocentesis, Hyaluronic acid, Corticosteroid, TMJ Osteoarthritis, platelet rich plasma

*Erzurum Ağız ve Diş Sağlı̆̆ı Merkezi , Ağız Diş ve Çene Cerrahisi Kliniği,

${ }^{* *}$ Gaziantep Üniversitesi, Diş Hekimliği Fakültesi, Ağız Diş ve Çene Cerrahisi AD 


\section{GİRİş}

Osteoartrit; eklemde kartilaj ve çevre dokularda kötüleşmeye ve dejenerasyona neden olan, ağrı, fonksiyon kaybı ve güçsüzlük ile karakterize kronik bir hastalıktır. Temporomadibulareklem osteoartriti (TME-OA) genetik faktörler, bruksizm, travma gibibir çok mekanik ve biyolojik olaylara bağlı gelişir. Görülme sıklığı bayanlarda daha sıktır ve yaşla ilişkili olarak artış gösterir. ${ }^{1}$

TME-OA teşhisi, temporomandibular hastalıkların teşhis kriterlerine (Research Diagnostic Criteria forT emporomandibular Disorders (RDC/TMD))göre yapılır ve Axis I GroupIIIb sınıflamasında yer alır. Bu kriterlere göre TME-OA bulgu ve semptomları şu şekilde sıralanır: eklem ağrısı (eklemin lateral ve posterior palpasyonundaki ağrılar ve açma ve lateral hareketler esnasında oluşan ağrılar), krepitasyon eklem sesi ve eklemde kondil, artiküler fossa ve diskde gözlemlenen radyolojik değişimlerdir. ${ }^{2,3}$

Eklemdeki dejeneratif değişimleri ve ilişkili yapıları değerlendirmek için birçok farklı radyolojik metot kullanılmasına rağmen, konik ışınlı bilgisayarlı tomografi (CBCT) yüksek duyarlıı̆ından dolayı genellikle tercih edilmektedir. ${ }^{1-3}$

TME-OA tedavisinde artrosentezi ve çeşitli eklem içi ajan uygulamaları içine alan çeşitli cerrahi ve cerrahi olmayan uygulamalar literatürde yer almaktadır. Bu tedavilerin temporomandibular disfonksiyonlu hastalarda ağrı seviyelerinde azalma ve eklem fonksiyonlarında önemli oranda iyileşme sağladığı belirtilmektedir. ${ }^{1,2}$

Artrosentez işlemi eklem içerisindeki enflamatuar ürünleri uzaklaştırıp ağrıyı azaltmakta ve fonksiyonel iyileşme göstermektedir. ${ }^{4}$

Trombositten zengin plazma (PRP) deneklerden alınan tam kanın yüksek oranda santrifüj edilmesi ile elde edilen ve tam kandan 3-8 kat kadar fazla konsantrasyonda, çok sayıda büyüme faktörü içeren trombositlerinotolog solüsyonu olarak tanımlanmaktadır. PRP hücrelerin proliferasyonu, migrasyonu ve farklılaşması üzerinde etki ederek yeni kemik ve kartilaj üzerinde iyileştirici potansiyel etki gösterir, kondrojenik farklılaşma, matrix üretimi ve doku remodelasyonu üzerinde etki oluşturur. ${ }^{5,6}$

Hyaluronat ve hyaluronan olarak da adlandırılan hyaluronik asit (HA) bir glikozaminoglikandır. Eklemler içerisindeki kondrositler ve sinoviositler tarafından üretilmektedir. Osteoartritik eklemlerde HA konsantrasyonu ve moleküler ağırlığında \% 35-50 oranında azalma olduğu ve bu azalmanın eklemdeki osteoartritik değişimleri artırdığı belirtilmiştir. ${ }^{7} \mathrm{Bu}$ nedenle dejeneratif eklemlerde yapılan eklem içi HA uygulamalarında, düşük HA oranının yerine koyulması ve eklem içerisindeki endojen HA üretiminin artırılması amaçlanmaktadır. ${ }^{8}$ Farklı orjin, moleküler ağırlık, yarılanma ömrü ve üretim metotlarına sahip dejeneratif eklemlerde kullanılan, HA'nın birçok enjektable formu vardır. ${ }^{9}$ Bunlar içerisinde yer alan Hyalgan, düşük moleküler ağırlıkıdır ve proteoglikan sentezini artırarak, proenflamatuar kaskadı tetikler ve kondrositlerin proliferasyonu ve farklılaşmasını sağlar. ${ }^{10}$

Depomedrol, metilprednizolon asetattır ve glukokortikoid ajanlar içerisinde yaygın kullanım alanı bulmuştur. Kortikosteroid enjeksiyonlarının osteoartritikeklemlerde fonksiyonel iyileşme sağlamak ve ağrıyı erken dönemde azaltmak amacıyla sıklıkla kullanılabildiği çeşitli klinik çalışmalarda ve meta-analizlerde gösterilmiştir. ${ }^{11}$ Bazı araştırıcılar kortikosteroid enjeksiyonlarının stromelysin sentezini azaltarak artikülerkartilajdaki hasarı azalttığını belirtirken, ${ }^{12}$ bir grup araştırıcı ise mevcut eklem hasarında artışa neden olabilecek yan etkilere sahip olduğunu belirtmiştir. ${ }^{11}$

PRP'nin eklem içi enjeksiyonları diz, kalça gibi birçok eklemi içeren dejenerasyonların tedavisi için başarılı bir şekilde kullanılmasına rağmen ${ }^{13,14}$, TME-OA tedavisinde etkinliğini inceleyen sınırlı sayıda çalışmalar vardır. ${ }^{6,15-17} \mathrm{Bu}$ son dönem yapılan çalışmalarda PRP nin daha iyi klinik ve radyolojik iyileşme sağladığı ve ayrıca eklem sesi ve ağrılarda azalmanın yanı sıra ağız açma miktarlarındada artış sağladığı belirlilmiştir. 6,15-17

Son dönem yapılan bir çalışmada Hegap ve ark. ${ }^{18}$ TME-OA nin tedavisinde 3 seans PRP ve HA'nın eklem içi enjeksiyonlarını artrosentez yapmadan uygulamışlar ve 6 ve 12 aylık takiplerde ağrı ve eklem sesinde PRP grubunda daha iyi sonuçlar elde ettiklerini bildirmişlerdir.

Son dönemde yapılan bir çalışmada artrosenteze ilave olarak yapılan PRP ve HA enjeksiyonlarının klinik etkinliği uzun dönemde değerlendirilmiş ve gruplar arasında tüm parametrelerde istatistiksel olarak anlamlı bir fark gözlemlenmemiştir. ${ }^{25}$

Kortikosteroidlerin TME osteoartritinde kulanımını değerlendiren bazı çalışmalar olmasına karşın, genellikle bu çalışmalarda kısa dönem etkinlik incelenmiştir. ${ }^{19-20}$ Buna karşın yaptığımız literatür incele- 
mesinde TME osteoartritin tedavisinde eklem içi PRP ve kortikosteroidlerin kullanımını karşılaştırmalı olarak değerlendiren herhangi bir çalışmaya rastlanılmamıştır. $\mathrm{Bu}$ çalışmada bu konudaki eksikliğin giderilmesi amaçlanmıştır.

$\mathrm{Bu}$ çalışmanın amacı TME osteoartritin tedavisinde artrosentez işlemini takiben uygulanan PRP, HA ve $\mathrm{KS}$ enjeksiyonlarının TME in lateral ve posteriorpalpasyonda oluşturduğu ağrı üzerine olan etkilerinin karşılaştırmalı olarak uzun dönemde incelenmesidir.

\section{MATERYAL VE METOD}

Bu çalışma Atatürk Üniversitesi Diş Hekimliği Fakültesi Ağız Diş ve Çene Cerrahisi kliniğine başvuran ve dört TME-OA tedavi protokollerinden biri ile tedavi edilen hastalar üzerinde dizayn edilmiş ve yürütülmüştür.

Bu çalışma lokal etik komite tarafından onaylanmış, hastalar çalışma hakkında bilgilendirilmiş ve çalışmaya katılan tüm hastalardan bilgilendirilmiş onam formu imzaları alınmıştır.

$\mathrm{Bu}$ çalışmada TME-OA klinik ve CBCT bulgularına göre teşhis edilen, 16 yaş ve üzerinde olan, bu dört tedavi protokollerinden birini alan ve işlem öncesinde ve işlemden 12 ay sonraki takip periyodunda yeterli verileri mevcut olan hastalar dahil edilmiştir.

Hematolojik ve nörolojik hastalığı olan, enflamatuar ve konnektif doku hastalığı, baş-boyun bölgesinde malign bir hastalığa sahip olan, daha önceden TME osteoartriti ile ilşkili olmayan TME tedavisi ve kraniofasial cerrahi alan ve işlem öncesi ve takip peryodu süresince verileri kaydedilemeyen hastalar bu çalışmadan çıkarılmıştır.

Tüm hastalar rastgele bir şekilde 4 gruba ayrıldı: Kontrol, PRP, HA ve KS grupları. Tüm hastalara tedavi başlangıcında artrosentez işlemi uygulandı. Sadece artrosentez işlemi uygulanan hastalar kontrol grubunu oluşturdu. PRP, HA ve KS grubunda artrosentez işlemi uygulandıktan sonra her bir dejeneratif eklem için1 $\mathrm{ml}$ eklem içi ajan enjekte edildi. PRP grubunda ayda bir olmak üzere eklem içi enesteziyi takiben ilave 4 seans daha PRP enjeksiyonları uygulandı.

PRP elde etmek için literatürde manuel ve otomatik olarak birçok elde etme yöntemi belirtilmiş olmasına rağmen, biz 1999 'da Anitua ve ark. ${ }^{21}$ tarafından tanıtılmış tek aşamalı manuel santrifüj tekniğini çalışmamızda kullandık.
Temel değişkenler tedavi teknikleridir. Diğer değişkenler ise yaş ve cinsiyettir. Bireylerin yaş ve cinsiyetleri kaydedildi ve temel değişkenler ile aralarındaki ilişki istatistiksel analize tabi tutuldu.

\section{Artrosentez uygulaması}

Artrosentez için kullanılan referans noktaları, artroskobik incelemede kullanılan noktalara benzerdir (lateralkantus-tragus). Preaurikular bölgedeki cilt yüzeyi povidon iyot solüsyonu ile enfeksiyondan arındırıldı. İşlem için oluşturulan lateralkantus -tragus hattında, ilk iğne için $10 \mathrm{~mm}$ ön $2 \mathrm{~mm}$ alt kısma ve ikinci iğne için ise $20 \mathrm{~mm}$ ön $6 \mathrm{~mm}$ alt kısma denk gelen yere işaretleme yapıldı. Daha sonra \% 4 artekain ve adrenalin $(1: 100,000)$ içeren anestezik solüsyon (Ultracain DS forte) aurikülotemporal anestezi için kullanıldı ve eklem içerisine de bu anestezik madde verildi. 20 gaglık iğne eklem içi yıkama işlemi için giriş ve çıkış noktalarına yerleştirildi. 100 ml laktatlı Ringer solüsyonu eklem içindeki katabolitlerin elimine edilmesi için kullanıldı. Artrosentez tamamlanınca her bir eklem için $1 \mathrm{ml} \mathrm{PRP,} \mathrm{HA} \mathrm{ve} \mathrm{ya} \mathrm{KS} \mathrm{ajanları} \mathrm{eklem}$ içerisine verildi. Daha sonra iki iğne uzaklaştırıldı. Bu işlemler esnasında ve takip peryodu süresince herhangi bir komplikasyon gözlemlenmedi. İşlem sonrası ağrıyı azaltmak için hastalara parasetamol grubu ilaçlar reçete edildi. Hatalara işlem sonrası sıvı- yarı sıvı gıda tüketimi, yavaş ağız açma egzersizleri önerildi.

Temel sonuç değişkenleri temporomandibular eklemin lateral ve posteriorpalpasyonundaki ağrı skorları olup, bu parametre 5 dereceli ağrı skalası (0 = yok; 1 = hafif; $2=$ orta; $3=$ yoğun; $4=$ şiddetli) kulanılarak tedavi öncesi ve tedaviden sonraki 1 yılda değerlendirilmiştir. Tüm değerlendirmeler aynı cerrah tarafından yapılmıştır.

\section{İstatistiksel Analiz}

İstatistiksel analizler Windows için SPSS 17.0 versiyonu (SPSS INC., Chicago, IL, USA) ile yapıldı. P değeri 0.05 den küçük değerler istatistiksel olarak anlamlı kabul edildi. Gruplar arası karşılaştırma sonuçları Mann- Whitney U testi kullanılarak değerlendirildi.

\section{BULGULAR}

Bu çalışma 81 dejeneratif ekleme sahip 55 erişkin bireyden oluşmuştur. Bu hastaların yaşları 16 ile 73 arasında değişmektedir. Hastaların yaş ortalamaları ve ortalama takip periyodları sırasıyla, kontrol grubunda ortalama $35.08 \pm 14.84 \mathrm{yll}$ ve $12.92 \pm 2.47$ ay, PRP

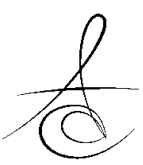


grubunda ortalama $32.22 \pm 14.33$ yıl ve $11.61 \pm 2.83$ ay, HA grubunda ortalama $28.08 \pm 11.12$ yl ve $12.77 \pm$ 0.73 ay ve KS grubunda ortalama $32.58 \pm 9.58$ yıl ve $11.92 \pm 1.38$ aydır (Tablo 1 ).

Yaş, cinsiyet ve takip periyotlarında gruplar arası anlamlı fark gözlemlenmemiştir ( $p>0.05$ ) (Tablo 1).

Kontrol grubu ile karşılaştıııldığında, PRP grubunda posterior TME palpasyonunda, HA grubunda ise lateral ve posterior TME palpasyonunda oluşan ağrı skorlarında istatistiksel olarak daha fazla iyileşme gözlemlenmiştir $(p<0.05)$. KS grubunda anlamlı bir iyileşme görülmemiştir ( $p>0.05$ ). PRP grubunda lateral TME palpasyonunda oluşan ağrı skorlarında ise, HA ve KS grupları ile karşılaştırıldığında istatistiksel olarak daha fazla iyileşme gözlemlenmiştir $(p<0.05)$ (Tablo 2). Tedavi sırasında ve takip peryodu süresince herhangi bir komplikasyon gözlemlenmemiştir. ve posterior TME palpasyonunda oluşan ağrı skorlarında istatistiksel olarak daha fazla iyileşme gözlemlenmiştir $(p<0.05)$. KS grubunda anlamlı bir iyileşme görülmemiştir ( $p>0.05$ ). PRP grubunda lateral TME palpasyonunda oluşan ağrı skorlarında ise, HA ve KS grupları ile karşılaştırıldığında istatistiksel olarak daha fazla iyileşme gözlemlenmiştir $(p<0.05)$ (Tablo 2). Bu sonuçlar, TM.E-OA tedavisinde TME palpasyonunda oluşan ağrının giderilmesinde diğer tedavi opsiyonlarına göre PRP'nin daha etkili bir iyileşme sağladığını göstermiştir.

TME ağrısının eklem sıvısındaki belirli enflamatuar mediatörlerin varlığıyla ilişkili olduğu da bazı çalışmalarda gösterilmiştir. Guven ve ark. ${ }^{22}$ ise 2015 de yaptıkları bir çalışmada artmış TNF-a seviyesinin TME de kemik ve kartilaj yıkımı ve sinovitisin patogenezi üzerinde etkili olabileceği belirtilmiştir. Artros-

Tablo 1. Yaş, cinsiyet ve takip sürelerinin gruplar arası karşılaştırma sonuçları

\begin{tabular}{|c|c|c|c|c|c|}
\hline & Kontrol & PRP & $\mathrm{HA}$ & $\mathrm{KS}$ & $\mathrm{P}$ değeri \\
\hline Yaş(yıl) & $35.08 \pm 14.84$ & $32.22 \pm 14.33$ & $28.08 \pm 11.12$ & $32.58 \pm 9.58$ & $>0.05$ \\
\hline Takip periyodu (ay) & $12.92 \pm 2.47$ & $11.61 \pm 2.83$ & $12.77 \pm 0.73$ & $11.92 \pm 1.38$ & $>0.05$ \\
\hline
\end{tabular}

Tablo 2. TME'in lateralpal pasyonunda oluşan ortalama ağrı skorları

\begin{tabular}{|c|l|l|c|}
\hline & & Pre-operatif & Post-operatif \\
\hline \multirow{3}{*}{$\begin{array}{c}\text { Lateral palpasyonunda oluşan } \\
\text { ağrı skorları }\end{array}$} & Kontrol & $1.17 \pm 1.49$ & $0.71 \pm 1.20$ \\
\cline { 2 - 4 } & PRP & $1.78 \pm 1.46$ & $0.31 \pm 0.82$ \\
\cline { 2 - 4 } & HA & $0.58 \pm 1.03$ & $0.77 \pm 0.27$ \\
\cline { 2 - 4 } & KS & $1.75 \pm 1.65$ & $0.90 \pm 1.29$ \\
\hline \multirow{3}{*}{$\begin{array}{c}\text { Posterior palpasyonunda } \\
\text { oluşan ağrı skorları }\end{array}$} & Kontrol & $0.67 \pm 1.20$ & $0.46 \pm 0.98$ \\
\cline { 2 - 4 } & PRP & $0.64 \pm 1.20$ & $0.11 \pm 0.52$ \\
\cline { 2 - 4 } & HA & $0.50 \pm 0.76$ & $0.08 \pm 0.39$ \\
\cline { 2 - 4 } & KS & $1.15 \pm 1.66$ & $0.25 \pm 0.91$ \\
\hline
\end{tabular}

\section{TARTIŞMA}

Bu çalışmanın amacı, TME osteoartritin tedavisinde kullanılanan artrosentez işlemini takiben uygulanan PRP, HA ve KS enjeksiyonlarının TME in lateral ve posteriorpalpasyonda oluşturduğu ağrı üzerine olan etkilerinin karşılaştırmalı olarak uzun dönemde incelenmesidir. Gruplar arasındaki yaş, cinsiyet ve takip peryodu parametreleri arasında istatistiksel olarak anlamlı bir farklılık görülmemiştir. Böylece sonuçları etkileyebilecek potansiyel bir etki tedavi başlangıcında ortadan kaldırıldığı için, tek değişken tedavi teknikleri kalmıştır.

Çalışmamızda elde edilen sonuçlara göre; kontrol grubu ile karşılaştırıldığında, PRP grubunda posterior TME palpasyonunda, HA grubunda ise lateral kopik çalışmalar TME ağrısının altındaki nedenin sinoviyum, kapsül veya retrodiskal dokulardaki enflamasyon olduğunu doğrulamıştır. Enflamatuvar ağrı mediyatörlerinin önemli konsantrasyonları ağrılı TME disfonksiyonlu hastaların sinoviyal sıvısında bulunmuştur. ${ }^{23}$

Klinik iyileşmelerin genel olarak artrosentezi takiben sağlandığı düşünülsede, PRP nin ilave iyileşme üstünlüğü PRP'nin biyolojik iyileşme mekanizması ile açıklanabilir. Yani, artrosentez işlemi, TME problemlerinin tedavisinde yaygın ve etkili bir şekilde kullanılıyor olmasına rağmen, ${ }^{4,6}$ etkisinin geçici olduğu ve eklemde yapısal iyileşme sağlamakta yetersiz olduğu belirtilmektedir. Bu yüzden de biyolojik etkinliğe sahip ve doku rejenerasyon özelliği olan eklem içi enjeksiyon ajanlarının kullanımı yaygın olarak kullanılmaktadır ve

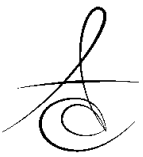


bu ajanlar kıkırdaktaki dejenerasyon eğilimini durdurarak yeniden eklem yüzeyini remodelize edebilirler. ${ }^{6,24}$ $\mathrm{Bu}$ amaçla TME-OA tedavisinde PRP, HA ve KS gibi farklı ajanlar eklem içi uygulamalarda kullanılmaktadır.

Anitua, sinoviyal hücre biyolojisini düzenleyerek, PRP'ninosteoartritteterapatik etki oluşturacağını ve çeşitli büyüme faktörleri içermesi ile eklem içi uygulamalardaanjiogenezisi stabilize edilip, düşük HA konsantrasyonunu artırılabildiği belirtmiştir. ${ }^{21}$ Yapılan son dönem çalışmalarda da PRP'nin hasarlı eklem yüzeyini tamir edebildiği ve klinik skorlarda da iyileştirici etki sağladığı belirtilmiştir. ${ }^{6,25}$

TME hastalıklarının tedavisinde PRP'nin kulanımını içeren çalışma sonuçları, bizim çalışma sonuçlarımız ile genel olarak uyumludur.Pihut ve ark. ${ }^{15}$ ve Hancı ve ark. ${ }^{16}$ PRP tedavisi ile ağrıda önemli oranda iyileşmeler gözlemlemişlerdir.

HA grubundaki pozitif iyileşme skorları literatürdeki bazı çalışmalarla uyumlu olduğu gözlemlenmiştir. Guarda-Nardini ve ark. ${ }^{9}$ ve Manfredini ve ark. ${ }^{24}$ yaptıkları çalışmalarda, TME-OA hastalarında uygulanan 5 seanslık HA enjeksiyonları ile ağrıda, çiğneme etkinliğinde ve bir çok klinik parametrede önemli iyileşme skorları elde etmişlerdir.

TME-OA'li hastalarda PRP ve HA enjeksiyonlarının etkinliğini değerlendiren tek bir çalışma mevcuttur. Artrosentez yapılmadan uygulanan bu eklem içi enjeksiyonları kullanan Hegap yaptığı bu çalışmada ${ }^{18}$, PRP'nin HA enjeksiyonlarına göre ağrı ve eklem sesinde daha pozitif iyileşme skorları elde ettiği belirtilmiştir ve bu bulgular da bizim çalışmamızın sonuçları ile uyumludur.

Wenneberg ve ark. ${ }^{20}$ yaptıkları çalışmalarda, TME-OA'li hastalarda KS enjeksiyonlarının 8 yıllık takipte uzun dönem etkileri incelemişler ve klinik skorlarda önemli oranda iyileşme ve kondiler erozyonda remodelasyon gözlemlemişlerdir. Bu çalışma sonuçları, bizim çalışma sonuçları ile uyuşmamaktadır. Bu sonuçlardaki farklılık, farklı takip süreleri, farklı seanslar, artrosentez işleminin yapılıp yapılmamasına bağlı olarak geliştiği söylenebilir. Aksine diz eklemleri için plasebo grubuna karşı, KS enjeksiyonlarının kullanıldığı bir çalışmada ise, bizim bulgularımızı destekleyecek şekilde ilave bir pozitif etki gözlemlenmemiştir. ${ }^{11}$ Literatürde PRP ve KS enjeksiyonlarının etkinliğini osteoartritik eklemlerde değerlendiren herhangi bir çalışmaya rastlanmamıştır. Bu yüzden de çalışmamızın sonuçlarını tartışma imkanı bulunamamıştır.
Sonuç olarak, bu çalışmanın bulguları artrosentezi takiben uygulanan eklem içi PRP enjeksiyonlarının kontrol, HA ve KS gruplarına nazaran TME palpasyonundaki ağrı üzerinde daha fazla iyileşme sağladığını göstermiştir

\section{KAYNAKLAR}

1. Liu F, Steinkeler A. Epidemiology, diagnosis, and treatment of temporomandibular disorders. Dent Clin North Am 2013;57:465-79.

2. Cömert Kılıç $S$, Kılıç $N$, Sümbüllü $M A$. Temporomandibular joint osteoarthritis: cone beam computed tomography findings, clinical features, and correlations. Int J Oral Maxillofac Surg 2015;44: 1268-74.

3. Dworkin SF, LeResche L. Research diagnostic criteria for temporomandibular disorders: Review, criteria, examinations and specifications, critique. J Craniomand Disord 1992;6:301-55.

4. Alpaslan C, Bilgihan A, Alpaslan GH, Guner B, Ozgur Yis M, Erbas D. Effect of arthrocentesis and sodium hyaluronate injection on nitrite, nitrate, and thiobarbituric acid-reactive substance levels in the synovial fluid. Oral Surg Oral Med Oral Pathol Oral Radiol Endod 2000;89:686-90.

5. Marx RE. Platelet-rich plasma: evidence to support its use. J Oral Maxillofac Surg 2004;62:489-96.

6. Cömert Kılıç $S$, Güngörmüş $M$, Sümbüllü $M A$. Is arthrocentesis plusplatelet-richplasmasuperiorto arthrocentesis alone in the treatment of TMJ osteoarthritis? A randomized clinica Itrial. J Oral Maxillofac Surg 2015; 73:1473-83.

7. Dahl LB, Dahl IM, Engstrom-Laurent A, Granath K. Concentration and molecular weight of sodium hyaluronate in synovial fluid from patients with rheumatoid arthritis and other arthropathies. Ann Rheum Dis 1985;44:817-22.

8. Bagga H, Burkhardt D, Sambrook P, March L. Long term effects of intraarticular hyaluronan on synovial fluid in osteoarthritis of the knee. J Rheumatol 2006;33:946-50.

9. Guarda-Nardini L, Cadorin C, Frizziero A, Ferronato G, Manfredini D. Comparison of 2 hyaluronic acid drugs for the treatment of temporomandibular joint osteoarthritis. J Oral Maxillofac Surg 2012;70:2522-30. 
10. Kawasaki K, Ochi M, Uchio Y, Adachi N, Matsusaki M. Hyaluronic acid enhance sproliferation and chondroitin sulfate synthesis in cultured chondrocytes embedded in collagen gels. J Cell Physiol 1999;179:142-8.

11. Bellamy N, Campbell J, Robinson V, Gee T, Bourne $\mathrm{R}$, Wells $\mathrm{G}$. Intraarticular corticosteroid for treatment of osteoarthritis of the knee. Cochrane Database Syst Rev 2006; 2: CD005328.

12. Lomonte $A B$, de Morais MG, de Carvalho LO, Zerbini CA. Efficacy of Triamcinolone Hexacetonide versus Methylprednisolone Acetate Intraarticular Injections in Knee Osteoarthritis: A Randomized, Double-blinded, 24-week Study. J Rheumatol 2015; 42:1677-84.

13. Kon E, Mandelbaum B, Buda R, Filardo G, Delcogliano M, Timoncini A, Fornasari PM, Giannini S, Marcacci M. Platelet-rich plasma intra-articular injection versus hyaluronic acid viscosupplementation as treatments for cartilage pathology: from early degeneration to osteoarthritis. Arthroscopy 2011;27:1490-501.

14. Filardo G, Di Matteo B, Di Martino A, Merli ML, Cenacchi A, Fornasari P, Marcacci M, Kon E. Platelet-Rich Plasma Intra-articular Knee Injections Show No Superiority Versus Viscosupplementation: A Randomized Controlled Trial. Am J Sports Med 2015; 43:1575-82.

15. Pihut M, Szuta M, Ferendiuk E, ZenczakWieckiewicz D. Evaluation of pain regression in patients with temporomandibular dysfunction treated by intra-articular platelet-rich plasma injections: a preliminary report. Biomed Res Int 2014;2014:132369.

16-Hanci M, Karamese M, Tosun Z, Aktan TM, Duman $\mathrm{S}$, Savaci N. Intra-articular platelet-rich plasma injection for the treatment of temporomandibular disorders and a comparison with arthrocentesis. J Craniomaxillofac Surg 201543:162-6.

17. Kutuk N, Bas B, Soylu E, Gonen ZB, Yilmaz C, Balcioglu E, Ozdamar S, Alkan A. Effect of platelet-rich plasma on fibrocartilage, cartilage, and bone repair in temporomandibular joint. J Oral Maxillofac Surg. 2014;72:277-84.

18. Hegab AF, Ali HE, Elmasry M, Khallaf MG. PlateletRich Plasma Injection as an Effective Treatment for Temporomandibular Joint Osteoarthritis. J Oral Maxillofac Surg. 2015;73:1706-13.
19. Kopp S, Carlsson GE, Haraldson T, Wenneberg B. Long-term effect of intraarticular injections of sodium hyaluronate and corticosteroid on temporomandibular joint arthritis. J Oral Maxillofac Surg. 1987;45:929-35.

20. Wenneberg B, Kopp S, Gröndahl HG. Long-term effect of intra-articular injections of a glucocorticosteroid into the TMJ: a clinical and radiographic 8-year follow-up. J Craniomandib Disord. 1991;5:11-8.

21. Anitua E, Sanchez M, Nurden AT, Zalduendo MM, de la Fuente M, Azofra J, Andia I.

Platelet-released growth factors enhance the secretion of hyaluronic acid and induce hepatocyte growth factor production by synovial fibroblasts from arthritic patients. Rheumatology (Oxford). 2007; 46: 1769-72.

22. Güven O, Tekin U, Salmanoğlu B, Kaymak E. Tumor necrosis factor-alpha levels in the synovial fluid of patients with temporomandibular joint internal derangement. J Craniomaxillofac Surg. $2015 ; 43: 102-5$.

23. Quinn JH, Bazan NG. Identification of prostaglandin E2 and leukotriene B4 in the synovial fluid of painful, dysfunctional temporo mandibular joints. J Oral Maxillofac Surgery 1990;48:968-71.

24. Manfredini D, Rancitelli D, Ferronato G, GuardaNardini L. Arthrocentesis with or without additional drugs in temporomandibular joint inflammatorydegenerative disease: comparison of six treatment protocols. J Oral Rehabil 2012; 39:245-51.

25. Cömert Kılıç $S$, Güngörmüş $M$. Is arthrocentesis plus platelet-rich plasma superior to arthrocentesis plus hyaluronic acid for the treatment of temporomandibular joint osteoarthritis: a randomized clinical trial. Int J Oral Maxillofac Surg 2016; 45:1538-44.

\author{
Yazışma Adresi \\ Dr. Songul CÖMERT KILIÇ \\ Ağız ve Diş Sağlığı Merkezi, \\ Ağız Diş ve Çene Cerrahisi Kliniği, \\ Yakutiye/ ERZURUM \\ Tel: +90.442 .2334590$ \\ Fax: +90.442 .2360945$ \\ e-mail: drsckilic@yahoo.com.tr
}

